\title{
EXPLORING THE FUTURE OF THE LEARNING MANAGEMENT SYSTEM
}

\section{Kristin Kipp}

Boise State University

Address all correspondence to: P.O. Box 915, Indian Hills, CO 80454;

Phone: 303-301-4538;

Email: kristin@beyondsitandclick.com

\begin{abstract}
In the past decade, learning management systems (LMSs) have become the standard on college campuses. However, some professors are growing increasingly frustrated with the LMS and its limitations, especially within online classrooms. The $2017 \mathrm{New}$ Media Consortium Horizon Report for higher education identifies next-generation LMSs as a key trend in the next two to three years. This article explores issues with current LMSs along with several possible visions for the next-generation LMS.
\end{abstract}

KEY WORDS: learning management system (LMS), personalized learning environment (PLE), next-generation learning management system (NGLMS), next generation digital learning environment (NGDLE), open learning network (OLN)

\section{EXPLORING THE FUTURE OF THE LEARNING MANAGEMENT SYSTEM}

The use of a learning management system (LMS) at the university level has been growing steadily since the launch of Blackboard in 1998 (De Smet, 2012). An LMS allows professors to share content, grade assignments, facilitate discussions, and more, both in online and face-to-face courses. As of 2015, Brown and coworkers reported that $99 \%$ of college campuses have a learning management system (Brown et al., 2015), where 85\% of faculty use an LMS with $56 \%$ of those reporting that they use it every day and $74 \%$ saying that they find it useful. However, despite widespread use, some professors are growing frustrated with the traditional LMS and the ways that its functionality limits pedagogy (Lane, 2009; Mott and Wiley, 2009; Mott, 2010; Thackaberry, 2017). They envision a future where the LMS takes on a new, more student-centered form.

Institutions are already beginning to explore what a post-LMS world might look like. Western Governors University, a competency-based online program, launched without an LMS at all. Instead, they host an internal website for each course that fully replaces the functions of an LMS (Thackaberry, 2017). At the University of Mary Washington 
(Fredericksburg, VA), a personalized domain for each student has replaced the LMS in a system they call a "Domain of One's Own" (Adams Becker et al., 2017). These LMS alternative systems solve some of the key problems of a traditional LMS but alone cannot completely replace the functionality of a traditional LMS.

The New Media Consortium 2017 Horizon report for higher education identified the nextgeneration LMS (NGLMS) as a key trend in the next two to three years (Adams Becker et al., 2017). They predict that these next-generation systems will "[enable] educators to unbundle all of the components of a learning experience and allow them to remix open content and educational apps in unique and compelling ways" (Adams Becker et al., 2017, p. 45). It would be a fairly dramatic shift from a self-contained LMS to a combination of applications chosen based on student and professor needs. Although the Horizon report admits that these systems are currently "more aspiration than reality," a growing number of theorists are imagining what the NGLMS could look like and some universities are even beginning to create prototypes. The implications for pedagogy in university classrooms, both face-to-face and online, could be significant.

\section{THE TRADITIONAL LEARNING MANAGEMENT SYSTEM}

Before looking into the future of learning management systems, it is important to fully understand why these systems have become so popular in university classrooms. An LMS is first and foremost a tool that is focused on efficiency (Mott, 2010). The LMS allows professors to quickly distribute course content and announcements. Students can submit assignments to the LMS through digital dropboxes and professors can grade and return their work within the system. At their best, an LMS also allows students to collaborate in a safe, interactive digital space (Malikowski et al., 2007). Their functionality has led to widespread adoption and many professors could not imagine teaching without an LMS. The development of the modern LMS is also what has allowed the explosion of online and blended learning in today's world. The LMS allows a course to live in a fully digital space.

\section{PROBLEMS WITH LMS USE}

Although there are significant benefits to using a learning management system, many professors are starting to question if the LMS is the best system for learning. As Thackaberry (2017) points out, "The practical fact remains that most colleges and universities utilize LMS and most folks who work with them are not particularly enthusiastic about them."

One of the key issues with many LMSs is that they were built for administrative duties, not for facilitating learning. Most traditional LMSs are good at managing the paperwork inherent in teaching and learning. However, in many ways they are instructor-centric with content delivery and gradebook tools being their primary function and content creation, 
collaboration, and communication tools seen as their secondary purpose. Mott (2010) points out that the "LMS is primarily a tool set for administrative efficiency rather than a platform for substantive teaching and learning activities." Sclater (2008, p. 2) elaborates by explaining that "even the term learning management system suggests disempowerment-an attempt to manage and control the activities of the student by the university."

Beyond the problem of being too instructor-centric, other critics point out that an LMS has a way of defining and limiting pedagogy. Lane (2009, Introduction, paragraph 2) points out that content management systems "are not pedagogically neutral shells for course content." By providing a default layout that highlights informational parts of the LMS, such as the announcements and static content pages, while hiding more interactive features, such as discussions and wikis by default, the LMS has directed the way that a course is taught rather than the professor directing it. Professors may never move into deeper use of the LMS. Instead, they become comfortable with those basic tools as their core pedagogy. The LMS subtly directs the pedagogy of the course and often not for the better. Watters (2014, paragraph 15) argues that, "Technology doesn't simply enable new practices; it shapes, limits, steers our practices, and then-and this is key-even when technology changes, those practices endure." In Watters' view, even when a campus moves to an updated version of an LMS with more interactive features or teaches professional development on more interactive tools within the LMS, old ineffective practices will endure because the original LMS became the norm. While universities are moving toward more learner-centric models, the LMS may be lagging behind and making that innovation more difficult (Brown et al., 2015).

A larger issue mentioned repeatedly by critics is that an LMS is a "walled garden," where only the invited can visit and collaborate (Casquero et al., 2010; Mott, 2010; Thackaberry, 2017). Even with a highly interactive, well-built LMS and strong pedagogy, the tool still exists behind a username and password. It is not open to the world and thus limits the possibility for real-world relevance in the learning environment (Mott and Wiley, 2009; Mott, 2010). As Watters (2014, paragraph 65) explained, "Ed-tech must not be about building digital walls around students and content and courses. We have, thanks to the Web, an opportunity to build connections, build networks, not walls." O'Hanlon (2007) pointed out that the walled garden actually protects students from outside dangers but others view the potential for collaboration with the outside world as more important. While the walled garden problem also exists within face-to-face classrooms, in today's networked world, it is possible and desirable to open up the classroom to more real-world applications. Universities must find a way to make that connected learning possible, and so far the LMS has not encouraged a significant level of openness. 
Because the LMS exists within that walled garden, there's also limited ability to create long-lasting community. At the end of a semester, a course is closed and sometimes even deleted. Any community that was built during the term is likely lost. Users would never tolerate that sort of 14-week cycle on Facebook (Mott and Wiley, 2009). Imagine if every 14 weeks

Facebook deleted its user's friends list. It would create a very disjointed, disconnected sense of community that the users would not tolerate for long. By closing an LMS course at the end of a term, learners have a similar experience. The LMS, in some ways, "institutionalizes a discrete, disjoined model of learning" (Mott and Wiley, 2009, p.10), which is the opposite of what most universities want to communicate to their students about learning.

\section{THE PERSONAL LEARNING ENVIRONMENT}

With all of the frustrations and limitations of learning management systems, theorists are beginning to imagine alternatives to the LMS. One alternative that has emerged is the personal learning environment (PLE). A PLE is a "Lego" approach to an LMS with each user choosing a set of modular tools that fits his or her own learning needs (Adams Becker et al., 2017). In theory, these modules could be chosen and combined by the students themselves. Sclater (2008, p. 4) says that the PLE would "encourage learners to draw the best from every environment." A learner might use one blogging tool, another wiki tool, and another discussion tool. Then, those tools would be pulled together by the student into one interface by use of modules or widgets similar to the design of the now defunct iGoogle (Casquero et al., 2010). Each user's modules would create a feed of activity that could be accessed by professors and compiled into a larger class feed.

The Domain of One's Own Project at the University of Mary Washington is an example of a personal learning environment (Watters, 2014). Students are assigned their own domain within the university when they first begin their coursework. The students then use that domain along with university Web hosting to create their own website. The site usually contains a digital portfolio of all of the student's work throughout their university career, providing the student a unique opportunity to cultivate their digital footprint. Professors include blog assignments within their courses and those blogs are also housed in the student's personal domain. Professors use an aggregator (most often RSS, referred to as really simple syndication) and tagging to pull blog entries into a central course website where students can collaborate. When the students reach the end of their coursework, their website content and domain remain their own. They continue to own the content and can continue to build on it throughout their lives. 
Another example of a personal learning environment in action was reported by Valtonen et al. (2012). Thirty-three vocational students in Finland created a PLE as a part of their studies. The students were given course credit for creating their PLE and had complete flexibility on what the site might contain, although their professors showed them how to use Ning as their core tool and also modeled using the site as a digital portfolio. Of the 33 students who participated, nine used their PLE as a way to mirror a traditional LMS. They uploaded assignments so that their professors could provide feedback. In many ways, the students were copying Moodle, a tool they were familiar with in other courses. Six of the students used their PLE as a space for reflection, focusing on blogs as a way to share their thinking about course content. Eleven of the students used their PLE as a space to share a digital portfolio, and all 33 included some element of collaboration in their PLE. Valtonen et al. (2012) pointed out that the students were highly influenced by their professor's directions, suggesting that the task of creating a PLE would have been very difficult on their own. Although most of the students found the PLE project rewarding, the fact that the sites so closely mirrored an LMS indicates that, even with a PLE, an LMS is a valuable tool for course content management that students will seek out if it is not already provided.

\section{BENEFITS AND ISSUES OF A PLE}

One of the key benefits of a PLE is that students are drawing the connections among the tools they choose to use (Mott, 2010). It requires a much deeper level of learning to consider the content, choose a tool to use, and then use that tool to process your learning. Each learner would have his or her own unique PLE depending on individualized content and needs. That level of customization is exceedingly difficult within most learning management systems.

Another key benefit of a PLE is that the system could persist beyond a student's university career. The system is student-created and thus student-owned. They could refer back to the resources within their PLE indefinitely (Mott, 2010).

Although the promise of a PLE is significant, there are also some fairly significant concerns in implementing a system with this level of personalization and customization. Many students are lacking the skills required to create a PLE. Sclater (2008, p. 6) pointed out that, "While independent learning is an admirable aspiration, many learners will continue to require considerable hand-holding in the online learning world. Leaving the management of their formal learning activities entirely to them will result in increased drop-out rates." Less tech-savvy faculty and students may also be overwhelmed by the idea of using multiple systems for multiple purposes. Even more so, university information technology (IT) departments may have significant trouble supporting so many different tools being 
used in different ways (Sclater, 2008). As Valtonen et al. (2012, p. 734) explained, the idea of a PLE may perhaps be "romantic constructivism," where the majority of students simply lack the skills to make a PLE a reality.

Another problem with the vision of a PLE is that the tools a student might want to use within a PLE do not currently have the module interoperability required for this sort of system. Critical to the development of PLE's is first interoperability (Casquero et al., 2010), meaning the ability for modules to communicate with each other and exist in an ecosystem together. Users would need to be able to easily combine multiple modules into a coherent whole that is useful for their learning as well as easily accessed by other learners. A set of standards for open architecture would be critical so that "small pieces loosely joined" in the PLE could be possible (Mott, 2010). Sclater (2008, p. 6) concluded that "PLE interoperability therefore currently seems a utopian vision." Until interoperability standards are widely accepted and tool creators embrace the vision of a PLE, implementing this sort of system may be impossible.

Another key issue with a PLE is its missing components. Within a PLE, there are no private spaces and no functionality for the necessary administrative functions of a course. While an LMS may over-rely on administrative functions and course efficiency, a PLE lacks those functions altogether. For a PLE to be successful, those functions would somehow have to be incorporated (Casquero et al., 2010).

Beyond these questions, universities also have to consider whether a formal PLE is necessary for student learning (Sclater, 2008). For students who are tech-savvy enough to build a PLE, one already exists. Those students are already using a variety of tools to meet their learning needs. Although those tools may not be housed in a central interface, the student's needs are still being met. For those who are not tech-savvy enough to create a PLE and curate a set of best-in-class tools for different purposes, another option that provides more support is required. After all, students are paying for university services. They should receive the support they need (Sclater, 2008).

\section{THE OPEN LEARNING NETWORK}

Given the significant concerns that a personal learning environment does not fully meet the needs of today's universities, another alternative that has emerged is the open learning network (OLN). An open learning network, unlike a PLE, is managed by a university. It tries to balance the needs of the university with the promise of the cloud (Mott, 2010) by creating a network that is partially public and partially private, and fully managed by a university's IT infrastructure. The OLN is a modular network like a PLE, but all of the modules live within the university-built system. The student information system, proprietary content, assessments, and gradebook live in a private portion of the open learning 
network. Then, blogs, wikis, portfolios, and open courseware live within the public portion of the OLN, accessible to the World Wide Web. Figure 1 demonstrates how an Open Learning Network might function on the web. Hypothetically, students could move seamlessly between the public and private portions of an OLN to meet their learning needs. The core tool of the OLN is a widget (Casquero, 2010), and student content from all relevant streams is compiled into one place using these widgets. Professors are able to pick what tools fit their needs. Perhaps they want a private wiki and a closed LMS for grading, but a public blog. Those elements could all be added in an OLN on an as-needed basis.

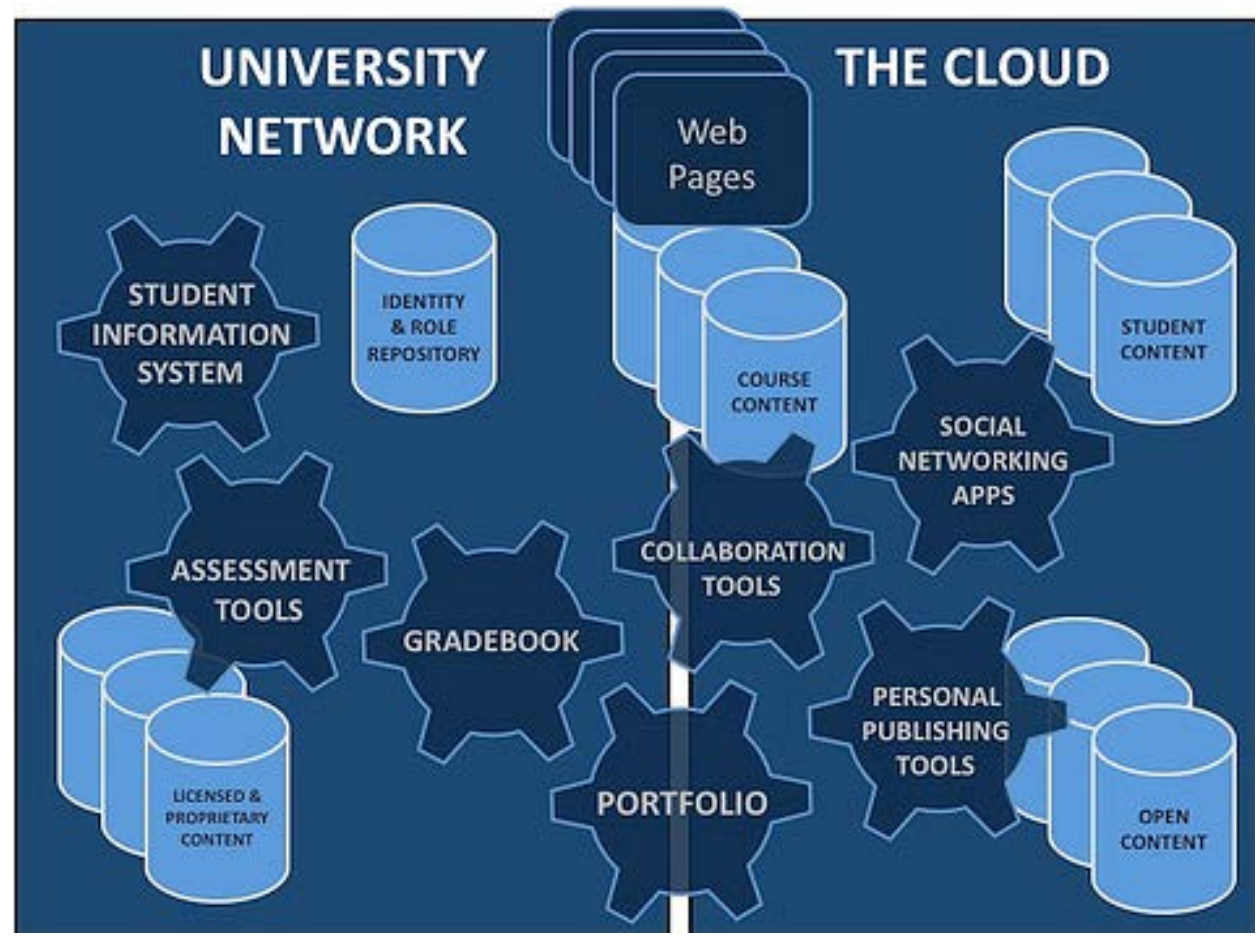

FIG. 1: Potential Schematic for an Open Learning Network. From "Open for Learning: The CMS and the Open Learning Network," by J. Mott and D. Wiley, 2009, In Education, 15, p. 7. CC BY 3.0 US.

\section{BENEFITS AND ISSUES OF AN OLN}

An open learning network has significant potential to meld the best of both worlds. Student information is kept private and course administrative functions live within a closed, private system, but the public portions of a course provide a vital connection with real-world learning. The outside world is welcomed in to enhance the learning experience (Mott and Wiley, 2009), while student information is kept private. For a university, the public information stream could also create a public relations benefit, with outside entities being able to clearly see the quality of the learning going on within the school's courses (Casquero et al., 2010). 
In addition, an OLN provides immense benefits to the professor. As in an LMS, the professor can decide what tools to utilize in which course sections. Professors still have access to the vital tools necessary for course administration but also have more diverse, collaborative tools available (Mott and Wiley, 2009). The potential for improved pedagogy is significant.

Unfortunately, no functional OLN is in existence to date (Mott, 2010), which is in part because of interoperability issues. Universities have not yet found a way to meld public and private tools in a way that is secure and user-friendly. Casquero et al., (2010) described a prototype system at the University of Basque Country (Leioa, Spain). However, the system relied on a combination of iGoogle and Google Apps for most of its functionality. Since iGoogle was discontinued in 2013, the system is no longer in place.

Another concern about the implementation of an open learning network is that since the system lives within a university it cannot continue beyond a student's graduation. As in an LMS, the community and resources that are built within the OLN would cease to exist at the end of a student's studies (Mott, 2010).

A final concern about implementation of an open learning network is student acceptance. Students who are tech-savvy already use a variety of tools. If a university attempts to bring those tools within one umbrella managed by the university, students may resist since the tool may have more limited functionality or a clunky interface (Sclater, 2008). If the most tech-savvy students do not want to use an OLN, it will have limited potential.

\section{A WAY FORWARD: THE PLE MEETS THE LMS}

Both the personal learning environment and the open learning network have significant potential. They provide the opportunity for students to use educational technology in a way that is personalized for deeper learning. Unfortunately, they are mostly theories at this point since the tools do not yet exist for creating these environments (Adams Becker et al., 2017). So what is an instructor to do in the meantime?

Thackaberry (2017, paragraph 13) suggested that we find a middle ground and "evolve the LMS from within." Thackaberry (2017, paragraph 21) argued that "no one likes the walled garden, but there's not a plausible open playground yet," so the way forward is, perhaps, a hybrid approach. First, instructors should utilize their learning management systems at a deep level, evolving beyond surface level functions to using more collaborative tools to their full potential (Malikowski et al., 2007). Then, where the LMS is lacking, instructors should use other tools to fill the holes (Thackaberry, 2017). Arvan (2009) agreed that we can "dis-integrate" the LMS as needed to get the best-of-class tools. We should use the tools in an LMS where they fit and go outside the LMS when it is best. An LMS can still be the core tool for a course, but blogs, wikis, and other Web 2.0 tools can be incorporated to 
bridge the gap between our current learning management systems and the nextgeneration systems that are developing. Ideally, over time, institutions will "partner with LMSs to reconceptualize the LMS as a platform" for more powerful learning (Thackaberry, 2017, paragraph 21).

In addition, a hybrid approach may require that universities consider new learning management system options. Just because a system has been used for a long time does not mean that it needs to stay. Each institution should look at its own needs and decide on the LMS that has the most functionality for its purposes (Thackaberry, 2017). New systems are available with exciting functions. Schoology is modeled after Facebook to provide users with an intuitive interface and social networking capabilities; that interface helps make the user interface much easier for students to learn (Schaffhauser, 2015). Canvas and Schoology both include an app store with an open application programming interface (API) that could significantly improve functionality by including outside tools (Empson, 2013; Schoology, 2017). These functions have the potential to bring elements of the PLE and OLN into an LMS environment in a powerful way. In Thackaberry's view, we may eventually "Chipotle the LMS" with each LMS having its own flavor and each institution having the ability to customize it for its own preferences (Thackaberry, 2017). However, it requires that professors explore the available functionality of tools and incorporate those that would enrich the student's experience within the LMS.

\section{CONCLUSIONS}

The promise for next-generation learning management systems is immense. They have the potential to move traditional learning management systems into a more user-centered world, focusing on the learner's experience first and foremost. Through the thoughtful use of public and private spaces, these next-generation systems could facilitate learning not just within their institutions but across the globe. Instructional designers, online teachers, and professors across the country should be collaborating now to help make these potentials into realities. LMS companies need to hear about your needs and how to create a system that will support learning rather than just administration. LMS developers should be considering how to build public and private spaces within an LMS and how to make content creation and collaboration front and center in updated LMS designs. In the meantime, while the next-generation LMS is in development, instructors should be doing everything they can to bridge the divide and bring some of the potential of PLEs and OLNs into today's classroom. By incorporating public blogs, wikis, and collaboration tools into their traditional LMS, they can bring the future a little closer and deepen student learning through courageous instruction. 


\section{REFERENCES}

Adams Becker, S., Cummins, M., Davis, A., Freeman, A., Hall Giesinger, C., and Ananthanarayanan, V. (2017), NMC Horizon Report: 2017 Higher Education Edition, Austin, TX: The New Media Consortium.

Arvan, L. (2009), Dis-Integrating the LMS, Educause Q., 32(2).

Brown, M., Dehoney, J., and Millichap, N. (2015), The Next Generation Digital Learning Environment: A Report on Research, ELI Paper, Louisville, CO: Educause.

Casquero, O., Portillo, J., Ovelar, R., Benito, M., and Romo, J. (2010), iPLE Network: An Integrated eLearning 2.0 Architecture from a University's Perspective, Interactive Learning Environ., 18(3), pp. 293-308.

De Smet, C., Bourgonjon, J., De Wever, B., Schellens, T., and Valcke, M. (2012), Researching Instructional Use and the Technology Acceptation of Learning Management Systems by Secondary School Teachers, Comput. Educ., 58(2), pp. 688-696.

Empson, R. (2013), Instructure Launches App Center to Let Teachers, Students Install Third-Party Apps across Learning Platforms. Retrieved March 3, 2018 from https://techcrunch.com/2013/04/12/instructure-launches-app-center-to-let-teachersstudents-install-third-party-apps-across-learning-platforms/.

Lane, L.M. (2009), Insidious Pedagogy: How Course Management Systems Affect Teaching, First Monday, 14(10).

Malikowski, S.R., Thompson, M.E., and Theis, J.G. (2007), A Model for Research into Course Management Systems: Bridging Technology and Learning Theory, J. Educ. Comput. Res., 36(2), pp. 149-173.

Mott, J. (2010), Envisioning the Post-LMS Era: The Open Learning Network, Educause Q., 33(1), pp. 1-9.

Mott, J. and Wiley, D. (2009), Open for Learning: The CMS and the Open Learning Network, In Educ., 15(2), pp. 3-22.

O'Hanlon, C. (2007), If You Can't Beat'em, Join'em: Educators Who Recognize How Much Social Networking Engages and Informs Kids Are Creating Their Own Sites as Learning Tools that Foster Collaboration among Students, Teachers, and Parents, THE J. (Technol. Horizons Educ.), 34(8), p. 38.

Schaffhauser, D. (2015), Four Features to Look for in a 21st Century LMS: Two Districts Share Their Experiences of Choosing a Learning Management System that Does a Lot More Than Help Teachers Post Assignments, THE J. (Technol. Horizons Educ.), 42(4), p. 19. 
Schoology (2017), Connect Everything Seamlessly. Retrieved March 3, 2018 from https://www.schoology.com/k-12/interoperability.

Sclater, N. (2008), Web 2.0, Personal Learning Environments, and the Future of Learning Management Systems, Res. Bull., 13(13), pp. 1-13.

Thackaberry, S. (2017), In Defense of the LMS. Retrieved February 16, 2018 from https://wcetfrontiers.org/2017/07/20/in-defense-of-the-Ims/.

Valtonen, T., Hacklin, S., Dillon, P., Vesisenaho, M., Kukkonen, J., and Hietanen, A. (2012), Perspectives on Personal Learning Environments Held by Vocational Students, Comput. Educ., 58(2), pp. 732-739.

Watters, A. (2014), Beyond the LMS [Web log comment]. Retrieved February 16, 2018 from http://hackeducation.com/2014/09/05/beyond-the-Ims-newcastle-university. 